11

\title{
Сравнительные измерения фотоэлектронной эмиссии в массивных образцах и островковых пленках серебра
}

\author{
(C) Н.Б. Леонов \\ Университет ИТМО, \\ 197101 Санкт-Петербург, Россия \\ e-mail: nikitaleonov@yandex.ru
}

Поступила в редакцию 23.05.2018г.

Исследована фотоэлектронная эмиссия серебряных островковых пленок, возбуждаемая лазерным импульсом длительностью $10 \mathrm{~ns}$ на трех длинах волн: 355, 532 и $1064 \mathrm{~nm}$. Показано, что для длин волн 355 и $532 \mathrm{~nm}$ фотоэмиссия островковых пленок существенно отличается от фотоэмиссии массивного образца. Для островковой пленки на длине волны $355 \mathrm{~nm}$ наблюдалась зависимость от энергии импульса, характерная для однофотонной эмиссии. Показано также, что поверхностный плазмонный резонанс в наночастицах оказывает существенное влияние на величину фотоэмиссии и характер ее зависимости от энергии лазерного импульса.

DOI: $10.21883 /$ OS.2018.10.46709.140-18

\section{Введение}

Металлические наночастицы обладают особыми свойствами, отсутствующими у массивных твердых тел. Сюда можно отнести, например, способность изменять форму при незначительном нагреве или при контакте с некоторыми жидкостями [1,2]. Сюда можно отнести также возможность возбуждения локализованного плазмонного резонанса в наночастицах под действием света. Эта особенность во многих случаях определяет возможность применения металлических наночастиц.

Изучение фотоэлектронной эмиссии металлических наночастиц представляет большой интерес как с точки зрения возможных приложений [3-5], так и с точки зрения фундаментальных исследований. Так, метод двухфотонной фотоэмиссионной спектроскопии применяется к исследованию электронных релаксационных процессов [6], а в [7] исследуется зависимость фототока от размеров наночастиц. Действительно, фотоэмиссия дает информацию, с одной стороны, об электронном состоянии системы (например, о работе выхода), с другой стороны - открывает широкие возможности для применения, например, в микроскопии [4].

Работа выхода серебра по данным [8] составляет $4.5-4.9 \mathrm{eV}$ для разных граней кристаллического серебра. И хотя в нашем случае мы имеем дело скорее с поликристаллическими структурами, работа выхода которых может быть немного меньше этих значений, источники видимого и инфракрасного света позволяют наблюдать лишь многофотонную эмиссию. Изучение многофотонной фотоэмиссии твердых тел началось вскоре после создания лазеров [9-11], и к настоящему времени проведено огромное количество исследований с разными лазерами и с разными объектами. Исследование наночастиц также естественно не могло пройти мимо применения к ним фотоэлектронных методов. В [12] показано теоретически, что фотоэмиссия из наночастиц может существенно отличаться от фотоэмиссии макроскопических структур (например, слоев металла), так как электромагнитное поле внутри частицы и вблизи поверхности наночастицы сильно возрастает при возбуждении локализованного плазмонного резонанса.

В настоящей работе нашей целью было сравнение многофотонной фотоэлектронной эмиссии из массивного образца с фотоэмиссией из наночастиц, составляющих островковую пленку. При эффективной толщине пленки $7 \mathrm{~nm}$ средний размер наночастиц был порядка 40-60 nm. Для не отожженной пленки частицы бесформенные, близко расположены друг к другу. Для отожженной пленки значительная часть частиц имеет круглую форму и расположены они на значительном расстоянии друг от друга. Тем не менее в обоих случаях свет возбуждает в наночастицах локализованные поверхностные плазмоны. Это дает основание надеяться на то, что характер фотоэмиссии с наночастиц будет несколько иным по сравнению с фотоэмиссией массивного образца.

\section{Эксперимент}

Измерения фотоэлектронной эмиссии серебряных пленок производились в самодельной вакуумной установке с безмасляной откачкой в вакууме не хуже $10^{-5}$ Torr. Для облучения использовался импульсный $\mathrm{Nd}$ :YAG-лазер. Все измерения были проведены при воздействии одиночных импульсов длительностью $10 \mathrm{~ns}$. Измерения проводились на трех длинах волн: 1064, 532 и $355 \mathrm{~nm}$. Максимальная энергия в импульсе на первой гармонике $(1064 \mathrm{~nm})$ была около 250 милиджоулей. Энергия импульса изменялась с помощью нейтральных фильтров и измерялась пироэлектрическим сенсором Ophir PE50BF-C. Диаметр пятна был 7-8 mm. Импульс фотоэлектронов снимался непосредственно с 


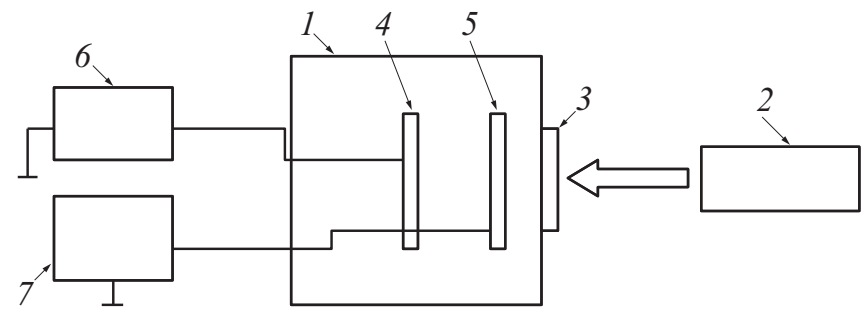

Рис. 1. Схема измерений фотоэлектронной эмиссии. 1 вакуумная камера, 2 - лазер, 3 - кварцевое окно, 4 образец, 5 - анод, 6 - осциллограф, 7 - источник питания.

подложки с нанесенной на нее пленкой и регистрировался осциллографом RIGOL с частотным диапазоном $500 \mathrm{MHz}$.

Воздействие одиночным импульсом было выбрано, вопервых, для того, чтобы уменьшить воздействие лазера на морфологию пленки [16], а также избежать зарядки, поскольку отожженные островковые пленки обладают очень большим сопротивлением [17]. Кроме того, изменение формы импульса сигнала в некоторых случаях позволяло судить о процессах, протекающих в пленке во время действия лазерного импульса.

Схема измерений фотоэмиссии показана на рис. 1.

Исследуемые образцы создавались в вакуумной установке с криогенной безмасляной откачкой PVD 75 (Kurt Lesker) при давлении не хуже $3 \cdot 10^{-7}$ Torr. Термически испаренное серебро осаждалось на подложки из шлифованного сапфира или полированного плавленого кварца. Перед установкой в камеру подложки очищались в ультразвуковой ванне сначала в чистом этаноле, затем в дистиллированной воде. Во время напыления подложки находились при комнатной температуре. Скорость напыления, а также эквивалентная толщина пленок контролировались кварцевыми микровесами. Скорость напыления была $0.01-0.03 \mathrm{~nm} / \mathrm{s}$. Толщина составляла несколько нанометров. Некоторые образцы прогревались в этой же установке до $200-250^{\circ} \mathrm{C}$ в течение $30 \mathrm{~min}$, что позволяло отжечь пленки, т. е. существенно изменить их морфологию [1].

Массивный образец представлял собой толстую ( $2-3 \mu \mathrm{m})$ пленку серебра, напыленную на такую же подложку. Чистота напыляемого серебра была 99.99\%.

Изменения морфологии островковых пленок контролировались с помощью растрового электронного микроскопа Merlin (Zeiss), а также с помощью спектров экстинкции и отражения, получаемых на спектрофотометрах СФ-56 (ЛОМО) или РМА-12 (Hamamatsu).

\section{Результаты}

Прежде чем начинать измерения фотоэлектронной эмиссии, вызванной лазерным импульсом, была определена красная граница фотоэффекта с помощью излучения ртутной лампы и набора фильтров. Поскольку
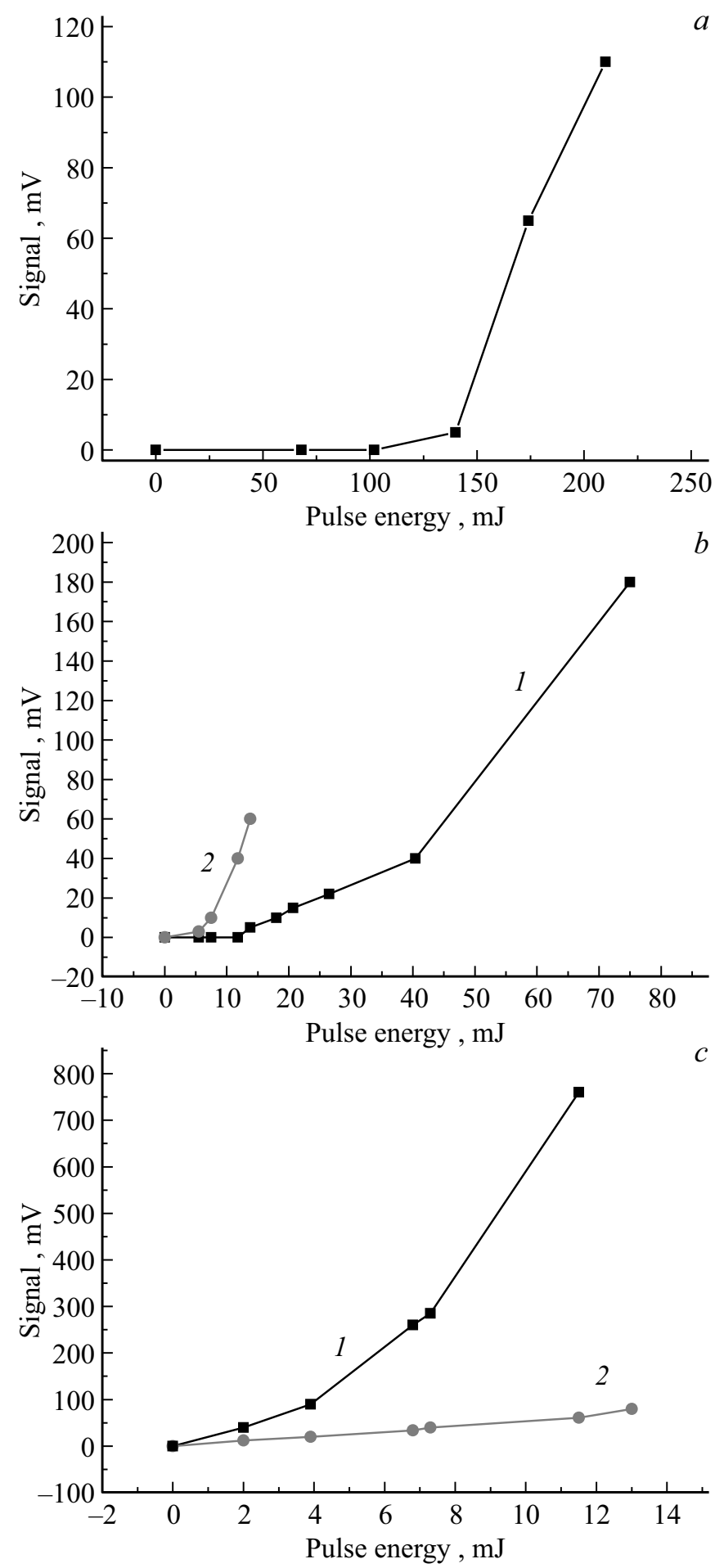

Рис. 2. Зависимость сигнала фотоэмиссии от энергии лазерного импульса для массивного образца $(b 1, c 1)$ и островковой пленки $(b 2, c 2) . a, b, c$ - длины волн $1.064,532,355 \mathrm{~nm}$ соответственно.

мощность лампы в диапазоне спектра 250-300 nm очень мала, невелика оказалась и точность определения красной границы. Тем не менее в нашем случае для массивного образца она имеет величину $4.4 \pm 0.1 \mathrm{eV}$, а для островковой пленки $-4.2 \pm 0.1 \mathrm{eV}$. Эти значения немного 


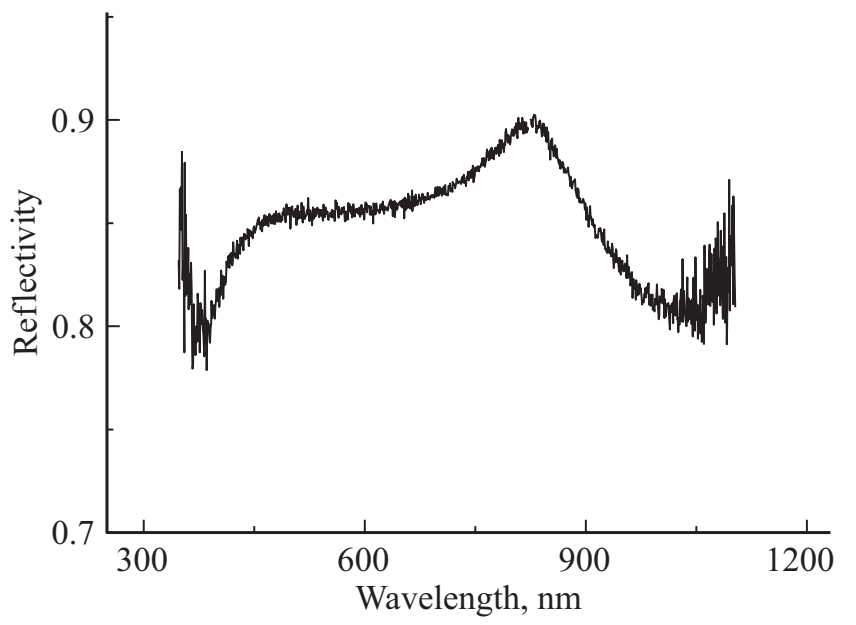

Рис. 3. Зависимость коэффициента отражения от длины волны для массивного серебра.

меньше $4.5-4.7 \mathrm{eV}$. Это предположительно связано с адсорбированными на поверхности образца остаточными газами, понижающими работу выхода. В [13] показано, что адсорбированные газы могут изменять красную границу на величину до $0.5 \mathrm{eV}$. Причины незначительного уменьшения работы выхода из наночастиц в островковой пленке по сравнению с массивным образцом описаны, например, в [14].

Нами были измерены зависимости амплитуды импульса фотоэлектронов от энергии лазерного импульса для трех длин волн как для массивного образца, так и для островковых пленок. Эти зависимости показаны на рис. 2.

На длине волны $532 \mathrm{~nm}$ (энергия кванта $2.3 \mathrm{eV}$ ) как для массивного образца, так и для островковой пленки зависимость величины фотоэмиссии от энергии импульса близка к квадратичной (рис. $2, b)$, что характерно для двухфотонного фотоэффекта [15]. При этом величина сигнала, полученного с островковой пленки больше, чем с массивного образца при одинаковой энергии лазерного импульса, а зависимость от энергии более крутая.

На длине волны $355 \mathrm{~nm}(3.5 \mathrm{eV})$ для массивного образца зависимость от энергии импульса также близка к квадратичной, хотя сигнал заметно больше, чем в предыдущем случае. Для островковой пленки ситуация совершенно иная. Сигнал существенно меньше, чем для массивного образца, а зависимость от энергии близка к линейной.

На длине волны $1064 \mathrm{~nm}$ эмиссия электронов начинается лишь при энергиях импульса, в несколько раз превышающих энергию импульса начала фотоэлектронной эмиссии для второй $(532 \mathrm{~nm})$ и особенно третьей $(355 \mathrm{~nm})$ гармоник. Поскольку отражение массивного образца для используемых нами трех длин волн отличается незначительно (рис. 3), можно предположить, что причиной такой разницы в величине фототока является природа фотоэмиссии. Для получения четырехфотонной фотоэмиссии с энергией фотона $1.17 \mathrm{eV}$ плотность мощности лазерного импульса недостаточно велика. Следовательно, остается предположить, что электронная эмиссия вызвана нагревом образца. Для первой гармоники $-1064 \mathrm{~nm}-$ можно было бы ожидать зависимость, близкую к экспоненциальной.

Снять зависимость от энергии импульса на длине волны $1.064 \mathrm{~nm}$ для островковой пленки нам не удалось - при энергиях импульса, которые достаточны для появления заметного сигнала (около $100 \mathrm{~mJ}$ ) - форма островков претерпевает серьезные изменения, пленка отжигается [16], и дальнейшие измерения проводятся фактически уже с другой пленкой.

\section{Обсуждение результатов}

Результаты, полученные для второй гармоники лазера (длины волны $532 \mathrm{~nm}$ ), хорошо согласуются как с более ранними измерениями, так и с предсказаниями теории $[9,11,12]$, а именно для двухфотонного фотоэффекта зависимость фототока от энергии лазерного импульса близка к параболической. Что касается больших значений фототока и более быстрого роста его в зависимости от энергии лазерного импульса для островковой пленки (рис. 2, $b$ кривая 2), то это тоже понятно в свете современных представлений о роли плазмонного резонанса в образовании фотоэлектрона. Действительно, серебряные островковые пленки обладают рядом свойств, не характерных для массивных образцов. Главной особенностью таких пленок является наличие поверхностного плазмонного резонанса, который можно возбудить с помощью света. При этом нужно иметь в виду, что положение этого резонанса существенно зависит от морфологии и структуры островков, а морфология и структура зависят от температуры пленки [1].

На рис. 4 показаны фотографии островковых пленок толщиной $7 \mathrm{~nm}$, полученные с помощью растрового электронного микроскопа - непосредственно после напыления (рис. $4, a$ ) и после отжига при $200^{\circ} \mathrm{C}$ в течение $30 \mathrm{~min}$ (рис. 4, $b$ ). На этом же рисунке показаны спектры экстинкции, соответствующие этим фотографиям.

Согласно [12], возбуждение светом и распад локализованных поверхностных плазмонов создают дополнительный канал для возбуждения и эмиссии электронов валентной зоны наночастицы. Фотоэмиссия из наночастиц может существенным образом отличаться от фотоэмиссии из массивного образца. Так как, во-первых, электромагнитное поле внутри частицы и вне ее вблизи поверхности наночастицы сильно возрастает при возбуждении локализованного поверхностного плазмона, а во-вторых, напряженность электрического поля, возбуждающего электрон, должна иметь возможно большую составляющую, перпендикулярную поверхности металла. Очевидно, это условие проще выполнить для наночастиц, чем для сплошных пленок, если свет падает под прямым углом. Попадая почти в максимум 

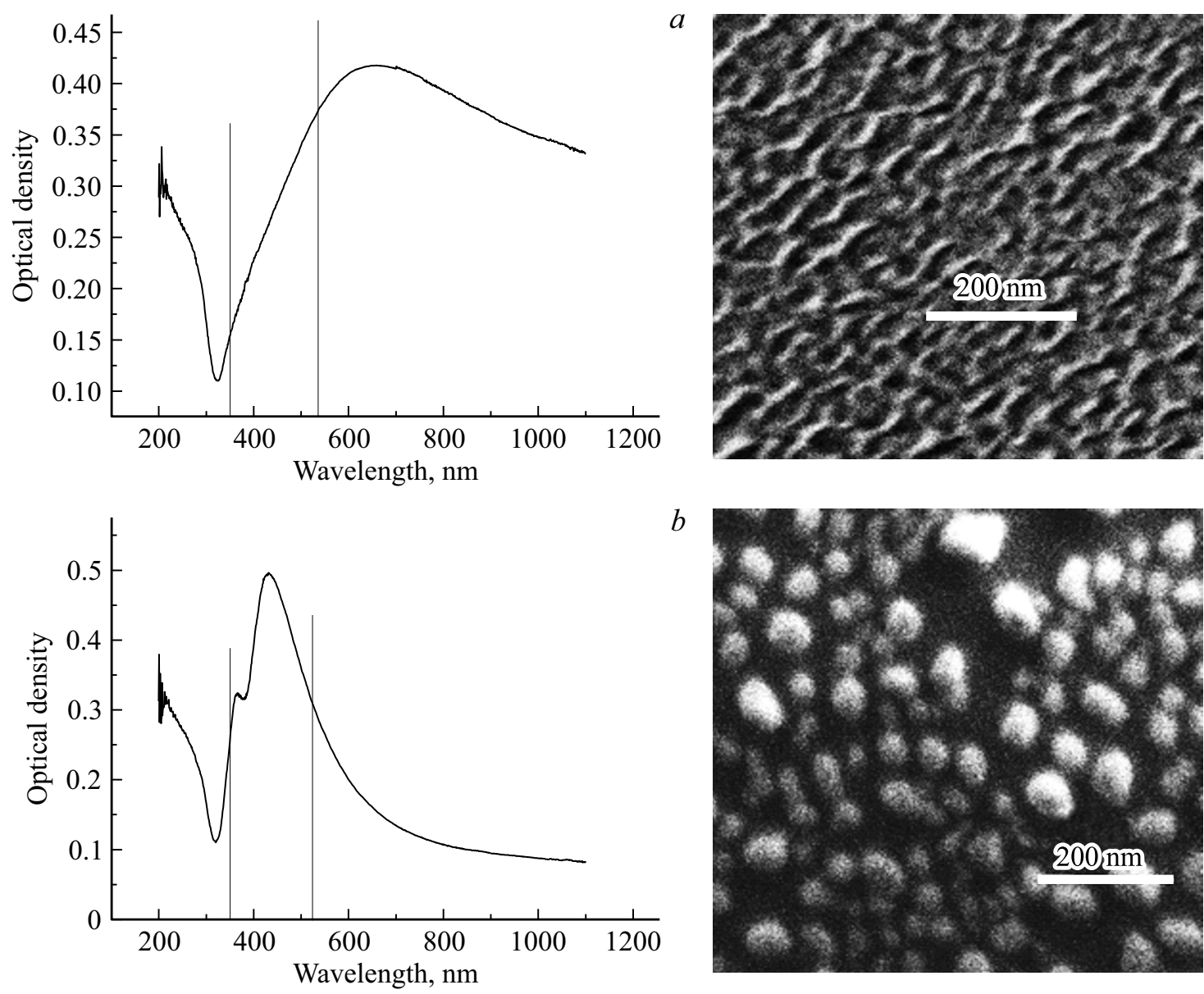

Рис. 4. Фотографии не отожженной $(a)$ и отожженной $(b)$ пленок серебра толщиной 7 nm на подложке из сапфира и соответствующие им спектры экстинкции. Вертикальными линиями на спектрах экстинкции показаны длины волн первой и второй гармоник.

поглощения (рис. 4,a), в островковой пленке свет с длиной волны $532 \mathrm{~nm}$ возбуждает в ней значительно больше электронов, чем в массивном образце. Этим и объясняется различие в зависимостях 1 и 2 на рис. $2, b$.

Наиболее интересным отличием поведения островковой пленки от массивного образца является характер зависимости величины сигнала от энергии импульса для третьей гармоники на длине волны $355 \mathrm{~nm}$ (энергия кванта $3.5 \mathrm{eV}$ ) . Измеренная для островковой пленки, эта зависимость почти линейна (в отличие от зависимости, снятой для массивного образца, которая близка к параболической), что характерно для однофотонного фотоэффекта (кривая 2 на рис. 2,c). Для объяснения этого явления можно предположить следующее: в процессе осаждения атомы не успевают занять наиболее энергетически выгодные состояния (образовать кристалл). В [18] с помощью электронограммы показано, что гранулы напыленной, но не отожженной пленки имеют большое количество дефектов, так что структура этих гранул близка к аморфной. Такие дефекты на поверхности островка могут привести к образованию значительного количества локализованных заполненных состояний, лежащих выше уровня Ферми. Если для эмиссии электронов с этих состояний достаточно энергии $3.5 \mathrm{eV}$, будет наблюдаться однофотонный фотоэффект. Поскольку опыты по определению красной границы с помощью ртутной лампы проходили на пределе чувствительности, по-видимому, мы не зарегистрировали слабый сигнал, определявшийся этими состояниями.

Уменьшение сигнала по сравнению с массивным образцом, по-видимому, объясняется слабым взаимодействием света с наночастицами - свет третьей гармоники попадает почти в минимум спектра экстинкции (рис. $4, a)$. Это подтверждается тем, что для отожженной пленки сигнал больше в 3-5 раз, поскольку оптическая плотность на этой длине волны для отожженной пленки значительно выше (рис. $4, b$ ). Характер зависимостей близок к таковому для не отожженной пленки, однако чрезвычайно трудно снять эти зависимости с достаточной степенью точности по причине очень высокого сопротивления пленки и, как следствие, зарядки образца [17].

Измерения фототока для массивного образца на длине волны $1064 \mathrm{~nm}$ показывают, что в данном случае фото- 
электронная эмиссия представляет собой процесс более сложный, чем просто результат нагрева металла лазерным импульсом. С одной стороны, очевидно, имеет место нагрев образца и, как следствие, термоэлектронная эмиссия. В пользу этого говорит тот факт, что при энергии импульса выше $150 \mathrm{~mJ}$ на осциллограмме импульса фотоэлектронов появляется „хвост“, свидетельствующий о том, что для остывания образца требуется время порядка нескольких наносекунд. Также незначительный нагрев образца с помощью печки (до $200^{\circ} \mathrm{C}$ ) приводит к росту сигнала в $1.5-2$ раза. С другой стороны, ход зависимости от энергии импульса заметно отличается от экспоненциального (рис. 2,a). Одной из причин такого отклонения может быть недостаточно гладкая поверхность образца. В процессе облучения неоднородности сглаживаются, что подтверждается микрофотографиями. Сглаживание поверхности должно приводить к уменьшению сигнала (отклонению зависимости от экспоненциальной). Другая причина может заключаться в наличии фотоэлектронной эмиссии, облегченной нагревом образца. В [11] указано, что в экспериментально наблюдаемый ток определенный вклад вносит одноквантовый процесс, идущий за счет температурного хвоста в распределении Ферми. В [19] описана эмиссия электронов из островковой пленки серебра под действием фемтосекундных импульсов с длиной волны $800 \mathrm{~nm}$, и зависимость от энергии импульсов носит характер степенной, а не экспоненциальной. Авторы объясняют этот феномен разогревом электронного газа с последующей фотоэлектронной эмиссией. В нашем случае при длительности импульса $10 \mathrm{~ns}$, очевидно, происходит разогрев всего образца, включая решетку. Тем не менее описанный механизм фотоэлектронной эмиссии вполне вероятен.

Автор выражает признательность В.Л. Комолову и T.А. Вартаняну за обсуждение работы, а также В.А. Полищуку за предоставление электронных микрофотографий образцов.

\section{Список литературы}

[1] Леонов Н.Б., Гладских И.А., Полищук В.А., Вартанян T.A. // Опт. и спектр. 2015. Т. 119. № 3. С. 116-121.

[2] Vartanyan T.A., Leonov N.B., Przhibelski S.G. // Opt. and Quant. Electron. 2017. V. 49. P. 127.

[3] Kasmi L., Kreier D., Bradler M., Riedle E., Baum P. // New Journal of Physics. 2015. V. 17. P. 033008.

[4] Masahiro Shibuta, Kana Yamagiwa, Toyoaki Eguchi, Atsushi Nakajima // Appl. Phys. Lett. 2016. V. 109. P. 203111.

[5] Mehran Vahdani Moghaddam et al. // ACS Nano. 2015. V. 9. N 4. P. 4064-4069.

[6] Lehmann J., Merschdorf M., Pfeiffer W., Thon A., Voll S., Gerber G. // Phys. Rev. Lett. 2000. V. 85. N 4. P. 2921-2924.

[7] Sipila M., Lushnikov A.A., Khriachtchev L., Kulmala M., Tervahattu H., Rasanen M. // New Journal of Physics. 2007. V. 9. P. 368
[8] Фоменко В.С., Подчерняева В.А. Эмиссионные и адсорбционные свойства веществ и материалов. Справочник. М., 1975. $320 \mathrm{c}$.

[9] Гладун А.Д., Барашев П.П. // УФН. 1969. Т. 98. С. $493-$ 524.

[10] Бродский А.М., Гуревич Ю.А. Теория электронной эмиссии из металлов М.: Наука, 1973.

[11] Анисимов С.И., Бендерский В.А., Фаркаш Д. // УФН. 1977. T. 122. C. $185-222$.

[12] Проченко И.Е., Усков А.В. // УФН. 2012. Т. 182. № 5. C. $543-554$

[13] Weghamp D. et al. // Appl. Phys. Lett. 2013. V. 103. N 15. P. 151603.

[14] Образцов А.Н., Волков А.П., Павловский И.Ю., Чувилин А.Л., Рудина Н.А., Кузнецов В.Л. // Письма в ЖЭТФ. 1999. T. 69. B. 5. C. 381-386.

[15] Uskov. A. et al. // Nanoscale. 2014. V. 6. P. 4716

[16] Вартанян Т.А., Леонов Н.Б. // Опт. и спектр. 2016. Т. 120. № 4. C. 662-667.

[17] Вартанян Т.А., Гладских И.А., Леонов Н.Б., Пржибельский С.Г. // ФТТ. 2014. Т. 56. В. 4. С. 783-789.

[18] Toropov N.A., Leonov N.B., Vartanyan T.A. // Phys. Stat. Sol. B. 2017. V. 254. N 10.

[19] Gloskovskii A. et al. // Phys. Rev. B. 2008. V. 77. P. 195427. 